\title{
Уроки истории: \\ модальности «закономерность», «сингулярность», «целое»
}

\author{
Розин В. М., \\ д. ф. н., профессор, главный научный сотрудник Института философии РАН, \\ rozinvm@gmail.com
}

\begin{abstract}
Аннотация: В статье обсуждаются условия мыслимости представления об уроках истории. Для опоры на эмпирический материал анализируются три кейса: как формулируют уроки истории 3. Бауман в книге «Актуальность холокоста», некоторые современные российские политологи-аналитики, И. Сталин в 20-30-х гг. прошлого столетия. Автор высказывает гипотезу, что целое, позволяющее получить правильные знания об уроках истории, задается двумя дополнительными дискурсами (культурологическим и цивилизационным). Обсуждаются особенности этих дискурсов и связанные с ними модальности мышления - закономерность и сингулярность. Высказанные соображения проверяются на эмпирическом примере послевоенной истории Германии и СССР.
\end{abstract}

Ключевые слова: история, уроки истории, мышление, реконструкция, культура, цивилизация, целое, закономерность, сингулярность, прогнозирование.

Почему вопрос о существовании уроков истории связывается с понятиями «культура» и «цивилизация»? На первый взгляд, это разные вещи. Но не будем спешить, подумаем сначала над примерами. Вот Зигмунд Бауман в книге «Актуальность холокоста» приводит такие уроки истории. Один из уроков Бауман видит в трансформации нравственности человека, попавшего в социальную машину фашизма. «Нынешнее значение холокоста заключено в уроке, который он содержит для всего человечества. Урок холокоста в том, с какой легкостью большинство людей, попавших в ситуацию, не оставляющую возможности для правильного выбора или делающую подобный выбор крайне дорогостоящим, уговаривают себя отвернуться от проблемы нравственного долга (или не могут уговорить себя ему следовать), принимая вместо этого принципы рационального интереса и самосохранения» [2, с. 243]. «Второй урок, - пишет в заключении Бауман, - говорит нам, что возвышение самосохранения над моральным долгом отнюдь не предрешено, не неминуемо и не неизбежно. Можно принуждать к такому выбору, но нельзя заставить его сделать, и поэтому нельзя переложить ответственность за содеянное на тех, кто оказал давление. Неважно, сколько людей предпочли моральный долг рациональности самосохранения - важно то, что некоторые сделали это. Зло не всемогуще. Ему можно сопротивляться. Свидетельство тех немногих, 
кто действительно воспротивился, разбивает власть логики самосохранения. Оно показывает, в чем, в конце концов, дело - в выборе. Интересно, сколько же людей должно возмутиться подобной логикой, чтобы сделать зло беспомощным? Существует ли волшебный порог сопротивления, за которым технология зла останавливается?» [2, c. 243].

Кроме того, Бауман показывает, что перерождению нравственности в Германии способствовали слабость демократии, сосредоточение всей государственной власти в руках одного человека, подавление нацистским государством общества, опасность утопических принимаемых правящей элитой картин и концепций.

Спросим теперь, что это за уроки, можно ли их учесть? Что предлагает Бауман в качестве панацеи: развитие демократии, блокирование утопических картин, контроль за государством, подавление элит, преследующих опасные для общества и человека цели, создание новых альтернативных социальных институтов, не допускающих все указанные реалии? Во-первых, даже если поставить перед собой подобные цели, достигнуть их очень трудно, практически невозможно. Во-вторых, оказывается, что социальные процессы, имевшие место в нацистской Германии, были вполне нормальными. «Мы уже знаем, пишет Бауман, - что ответственные за холокост институты, даже если считать их преступными, нельзя рассматривать как ненормальные или патологические в социологическом смысле. Теперь мы понимаем, что люди, чьи действия они направляли, не выходили за рамки установленных стандартов нормального поведения. Поэтому нам не остается ничего другого, как, вооружившись нашим новым знанием, вновь присмотреться к якобы нормальным образцам современного рационального действия» [2, с. 243].

Так вот, можно ли считать эти уроки истории уроками, если в практическом плане ими невозможно воспользоваться? Или речь у Баумана идет о пересмотре сознания? «Холокост возник и случился в нашем современном обществе, на высшей стадии нашей цивилизации, на пике культурных достижений человечества, и по этой причине это проблема общества, цивилизации и культуры. Самозаживление исторической памяти, которое происходит в сознании современного общества, по этой самой причине гораздо больше, чем просто оскорбление жертв геноцида. Это еще и знак опасной и самоубийственной слепоты. $\quad<\ldots>$ Данное исследование, - пишет Бауман, замысливалось как небольшой и скромный вклад в то, что в сложившихся условиях представляется давно назревшей задачей громадной культурной и политической важности; задачей по переводу социологических, психологических и политических уроков холокоста в самосознание и институциональную практику современного общества» [2, с. 10, 13].

Возьмем другой пример - уроки истории, которые постоянно формулируют наши серьезные аналитики, выступающие на «Эхе Москвы», в «Новой газете» или иногда в «Снобе». Правда, они звучат больше как констатации происходящего, а не уроки истории, но по функции подразумевается, что это уроки. «Вот, государственномонополистический капитализм, - говорит на «Эхе Москвы» главный редактор «Независимой газеты» Константин Ремчуков, - который построен в России, является государственно-монополистическим капитализмом бюрократического типа. После прихода к власти разновидность этого типа я называю «государственно-чекистский капитализм». Его особенностью является изменение структуры бюрократии, которая 
руководит государством... которая, собственно, этим монополистическим капитализмом рулит и в чьих интересах перераспределяется значительная часть произведенного продукта» [7].

«Некоторые аналогии, - пишет Владислав Иноземцев в «Снобе», - могут привести нас не к бывшим империям, а скорее к торговым корпорациям Нового времени, многие из которых выполняли функции государств (как британская Ост-Индская компания). Отличие заключается лишь в том, что в роли униженных и эксплуатируемых оказываются не жители заморских территорий, а все подданные того или иного национального лидера. Коммерческое государство - это система, в которой формальные инструменты государственного управления полностью подчинены задачам умножения богатств его руководителя, приближенных к нему лиц, их друзей и родственников, а также и всех тех, чья политическая лояльность необходима «большому боссу» для поддержания своей власти и обеспечения собственной безопасности. Здесь бессмысленно говорить о коррупции в общепринятом смысле слова, ведь таковая представляет собой попытку заработать на своем положении в той политической системе, которая предполагает служение public interests, а в коммерческом государстве сама эта задача даже не ставится. Обогащение политической верхушки является высшей целью системы, а извлечение выгод из своего служебного положения - ее фундаментальным императивом» [6].

Интересно, к кому обращены эти констатации, и если их рассматривать как уроки истории, то можно ли этими уроками воспользоваться?

В 20-30-х годах прошлого столетия И. Сталин решил, что СССР окружен врагами и война с буржуазными странами неизбежна, в том числе как очередной этап мировой революции. При том, что наша страна была разрушена революцией, и поэтому не имела оборонной промышленности и армии, обладающей современной военной техникой. В этой ситуации Сталин воспользовался уроком истории, говорящим, что побеждают те страны, которые создают опережающую время военную технологию. Была поставлена задача в кратчайшие сроки и любой ценой создать мощную оборонную отрасль. Для этого правительство, с одной стороны, организовало сбор средств (продажа за границу культурных ценностей, торговля зерном, отъем имущества церкви и прочее), с другой изучив американский опыт проектирования и строительства, оно заказывает фирме А. Кана за огромные для тех времен деньги (более 200 миллионов долларов) проектирование и строительство заводов двойного назначения (и для войны, и для гражданских целей, но, естественно, американским строителям об этом не говорили) ${ }^{1}[8$, c. 148-153].

Нельзя ли из сравнения этих трех уроков истории сделать вывод, что некоторая историческая или современная констатация, описывающая определенный социальный процесс, может выступить в роли урока истории только в том случае, если на основе этой констатации удается развернуть практическое социальное действие?

\footnotetext{
1 «После завершения строительства Сталинградского тракторного в 1930 году Саул Брон подписал с Каном контракт, который длился три года с 1930 по 1932, за время действия которого в России был построен 521 завод. Стоимость контракта составила два с половиной миллиарда долларов. По теперешним деньгам это 250 миллиардов!» [1].
} 
Холокост, утверждает Бауман, это «проблема общества, цивилизации и культуры». Думаю, не случайно употреблены эти три понятия. Но почему «цивилизация и культура», а не просто или «культура», как это часто говорят, или «цивилизация»? Возможно, обсуждение уроков истории предполагает именно дополнительность этих двух понятий. И вот почему. Что такое урок истории? Это не только определенный исторический процесс или событие, но такое, которое, во-первых, значимо для современности или ближайшего будущего, во-вторых, позволяет правильно действовать, воспользоваться этим процессом или событием практически. Если оно значимо и им можно воспользоваться, то, вероятно, предполагается повторяемость процессов и событий. Например, Сталин предполагал, что поскольку раньше технологически развитые страны побеждали в войне, то и СССР, если будет создана мощная оборонная промышленность, тоже победит. Здесь в плане мышления - процедуры экстраполяции, прогнозирования и предположение исторической закономерности. В плане же онтологических оснований, вероятно, происходит апелляция именно к понятию «цивилизация». Один из смыслов этого понятия - константность, воспроизводимость социальных отношений.

Напротив, один из смыслов понятия «культура» - кардинальная смена социальных отношений при переходе от предшествующей культуры к последующей (т. е. историческом переходе). Судя по тому, как эволюционировала мысль Баумана, первоначально он предполагал, что, поскольку холокост представлял собой нормальное социальное явление, а не аномальное социальное отклонение, он в той или иной мере может повториться и в будущем. «Я, - пишет Бауман, - пришел к выводу, что холокост стал итогом уникального столкновения факторов, которые сами по себе были совершенно банальными и обычными; и что вину за такое столкновение в значительной степени следует возложить на освободившееся от общественного контроля политическое государство с его монополией на средства насилия и его дерзкой инженерией, завершивших демонтаж всех неполитических ресурсов власти и институтов общественного самоуправления» [2, с. 14]. «Можно предположить, что в недалеком будущем вполне могут возникнуть ситуации, когда государству придется взять в свои руки социальное управление обществом - и тогда укоренившаяся и проверенная временем расистская позиция может снова пригодиться» [2, с. 104].

Но в дальнейшем Бауман понял, что социальная ситуация в мире очень изменилась, и поэтому просто экстраполировать закономерность, выявленную при анализе холокоста, невозможно. Он стал анализировать эти изменения, что видно, например, по работам «Текучая современность» и Ретротопия» [3; 4]. В данном случае Бауман мыслил скорее культурологически, а не в логике цивилизационной реальности. Смена культур - процесс только отчасти закономерный, здесь имеет место «становление нового как бы из ничего» (хотя и в поле предпосылок, но из последних культура не рождается, это только одно из условий становления). Становление новой культуры подчиняется логике и модальности сингулярности, правда, действующей на фоне определенных закономерностей. Формально подобное сочетание (сингулярности и закономерности) выглядит как противоречие, но мои реконструкции становления культур заставляют мыслить именно таким образом.

Не должны ли мы предположить, что понятия культуры и цивилизации при решении задач, подобных нашей (т. е. обсуждении природы уроков истории), являются 
дополнительными? Цивилизация позволяет нам мыслить исторические закономерности (соответственно, осуществлять экстраполяцию и прогнозирование), а культура - быть готовым обнаружить изменения, не укладывающиеся в предыдущие состояния истории. Но помимо указанных полярных смыслов этих двух понятий, вероятно, при обсуждении уроков истории нужно иметь в виду еще ряд смыслов. Мои исследования позволяют следующим образом охарактеризовать смыслы понятий «культура» и «цивилизация».

Культуру мы опознаем, задавая отличие одной культуры от других, анализируя видение мира и реальности, установившееся в данной культуре, обсуждая ее уникальность и целостность. Цивилизация связана с техникой, территорией, значением в миросистеме, обобщениями, которые касаются всех. Вот пример типичного цивилизационного дискурса. «Мироэкономика, — отмечает Валлерстайн, - находится под сильным спекулятивным гнетом, неподвластным основным финансовым учреждениям и контролирующим органам, например центральным банкам. Растет насилие, но усилий и возможностей власти недостаточно, чтобы решительно покончить с этим насилием. Значение моральных принципов, которые традиционно прививали своему народу государство и церковь, практически сошло на нет. Но, с другой стороны, тот факт, что система в кризисе, отнюдь не означает, что она вовсе отказалась от попыток действовать по-старому, по-привычному. Она пытается. Но в этом случае долговременные тренды все ближе приближаются к своим асимптотам, что только обостряет кризис. И все же большинство людей всегда предпочитают жить, как они привыкли. В этом есть смысл, но на очень небольшой срок» [5, с. 194]. «Несмотря на общий экономический рост, наблюдавшийся по всей миросистеме, - пишет он, - разрыв между странами ядра и периферии вырос как никогда. И, несмотря на то, что антисистемным движениям удалось прийти к власти, казалось, что великий единый порыв периода мобилизации сникал, как только движение захватывало власть в той или иной стране. Появилась новая привилегированная каста. Простых людей теперь просили воздержаться от агрессивных требований в адрес правительства, которое теперь было их представителем. Когда будущее стало настоящим, многие в прошлом пылкие борцы пересмотрели свои прежние позиции, и в движениях начались расколы. Именно сочетание давнего недовольства работой миросистемы с разочарованием в возможностях антисистемных движений переделать мир и привело к мировой революции 1968 года [5, с. 189] <..> Эта мировая революция ознаменовала собой конец долгого господства либерализма, тем самым сдвинув с привычного места геокультуру, благодаря которой все политические учреждения миросистемы были в целости и сохранности [5, с. 177].

В культурологическом дискурсе так рассуждать нельзя, нет, например, стран ядра и периферии, а есть разные культуры, нет просто людей, а есть представители той или иной культуры, которые видят и мыслят по-разному, нет вообще экономики, а есть национальная экономика, нет мирового господства либерализма, но есть разные культурно обусловленные политические системы.

Однако, обсуждая уроки истории, приходится мыслить в рамках обоих дискурсов, диалектически оперируя характеристиками каждого. Целое, позволяющее считать полученные знания правильными, на мой взгляд, задается как понятием культуры, так и понятием цивилизации. 
При этом необходимо учесть и такое обстоятельство. И культура, и цивилизация не эмпирические объекты, это предельные онтологии, данные нам в реконструкииях, в том числе исторических. Если знания о них и объективны, то в особом смысле гуманитарном и социальном. Эти знания невозможно проверить экспериментально, их истинность проверяется методологией исследования, а также привлекательностью для аудитории, которой такие знания предназначаются исследователем или которой они приглянулись. В этом плане и знания об уроках истории объективны в социогуманитарном смысле.

Но вернемся к работе Баумана. Анализируя уроки холокоста, он действительно рассуждал в рамках культурологического и цивилизационного дискурсов. С одной стороны, реконструировал уникальную историю Германии и евреев, особенности немецкого видения мира и мистико-мифологического культурного сознания, с другой анализировал немецкую социальность, близко к логике Валлерстайна, например, обсуждал, каким образом нацисты выстроили технологию, позволяющую, с их точки зрения, окончательно решить еврейский вопрос, как действие созданных нацистами социальных институтов ломало сознание немецких граждан, каким образом нацистское государство подавило общество.

«Современные условия, - пишет Бауман, - делают возможным появление “изобретательного” государства, способного заменить всю систему социального и экономического контроля на политическое управление и администрирование. Что еще более важно: современные условия обеспечивают необходимый “материал” для такого управления и администрирования. Современная эпоха, как мы помним, это время искусственного порядка и грандиозных социальных “дизайн-проектов”, время плановиков, визионеров и - в более общем плане - культивирующих нечто “садовников”, воспринимающих общество как целинную землю, которая должна культивироваться в соответствии с их планами» [2, с. 140]. «Два самых известных и страшных случая современного геноцида (фашизм и коммунизм) не изменили духу современности... Они породили огромный и мощный арсенал технологий и организаторского искусства. Они произвели на свет институты, которые служат однойединственной цели - смоделировать поведение человека до такой степени, что он будет продуктивно и энергично преследовать любую цель, причем независимо от того, получил ли он идеологическое обоснование или моральное одобрение со стороны тех, кто поставил перед ним эту цель. Эти мечты и усилия узаконивают монополию правителей на конечные результаты, а управляемым отводят роль средства. Они определяют большинство действий как средства, а средства должны подчиняться конечной цели тем, кто ее поставил, высшей воле, высшему знанию» [2, с. 117].

Этот дискурс Баумана явно цивилизационный, а не культурологический, хотя он позволяет, что Бауман отчасти и делает, привлекать, характеризуя холокост, и культурологические характеристики.

Интересно в этом плане, т. е. анализируя уроки истории, взглянуть на послевоенную историю Германии и России. Немецкое общество, правда, включенное в западную 
миросистему (план Маршалла и прочее ${ }^{2}$ ), прошло сложный и мучительный период переосмысления того, что произошло, осудило нацизм, приняло вину не по отношению к другим, а на себя, сформулировало и реализовало программы демилитаризации, компенсации пострадавшим, создания климата и практик, которые сделали бы невозможным повторение случившегося. Я бы обратил внимание на то, что шла двойная работа - в отношении сознания (кардинального пересмотра своих представлений) и практическая (в сфере образования, компенсации пострадавшим, демилитаризации и др.).

В отличие от Германии Россия была включена в другую миросистему (лагерь социализма), противостоящую капиталистической миросистеме. В силу идеологических соображений, заинтересованности правящей элиты в сокрытии того, что происходило, слабости и расколотости российского общества оно не сумело по-настоящему осмыслить ни культ личности, ни в целом программу построения социализма и те негативные социальные процессы, которые сопровождали ее реализацию.

В этом плане можно сказать, что если немецкое общество извлекло выводы из уроков истории, одновременно сформулировав эти уроки и приняв их, то российское общество по ряду причин не сумело правильно осмыслить свою историю и сформулировать уроки, вытекающие из этой истории.

Кажется, что в данном случае указанный результат можно объяснить чисто культурологически - различием немецкой и российской культур и истории. Однако не стоит забывать включенность этих культур в разные миросистемы и, возможно, разные социальные порядки. В одном случае были обновлены и заново введены в действие социальные институты, в другом их работа по-прежнему только имитировалась. Оба эти фактора принадлежат цивилизационному плану. Так что опять дополнительность этих двух способов мышления и модальностей.

\section{Литература}

1. Базаров В. Как американец Альберт Кан создал военно-промышленный комплекс Советского Союза. http://berkovich-zametki.com/2011/Zametki/Nomer8/Bazarov1.php.

2. Бауман 3. Актуальность холокоста. - М.: Европа, 2010. - 316 с.

3. Бауман 3. Текучая современность. - СПб.: Питер, 2008. - 240 с.

4. Бауман 3. Ретротопия. - М.: ВЦИОМ, 2019. - 160 с.

5. Валлерстайн И. Миросистемный анализ. - М.: Изд. Дом «Территория будущего», 2006. - $248 \mathrm{c}$.

6. Иноземцев В. Неэффективное. Безжалостное. Твое. Почему все мы живем в коммерческом государстве Путина // Сноб от 4 июля 2019 г. https://snob.ru/entry/179441/?from=mirtesen

\footnotetext{
2 «Заявленной США целью реализации плана было восстановление разрушенной войной экономики Европы, устранение торговых барьеров, модернизация промышленности европейских стран, вытеснение коммунистов из властных структур и развитие Европы в целом» [9].
} 
7. Ремчуков К. Выступление на «Эхе Москвы» в передаче «Особое мнение» от 4 апреля 2016 г.

8. Розин В. М. Техника и технология: от каменных орудий до Интернета и роботов. - Йошкар-Ола, ПГТУ, 2016. - 280 с.

9. https://ru.wikipedia.org/wiki/План_Маршалла/

\section{Reference}

1. Bazarov V. Kak amerikanec Al'bert Kan sozdal voenno-promyshlennyj kompleks Sovetskogo Soyuza [As an American, Albert Kahn created the military-industrial complex of the Soviet Union]. http://berkovich-zametki.com/2011/Zametki/Nomer8/Bazarov1.php. (In Russian)

2. Bauman Z. Aktual'nost' holokosta [Relevance of the Holocaust]. - Moskow: Europe, 2010. - 316 p. (In Russian)

3. Bauman Z. Tekuchaya sovremennost' [Fluid modernity]. SPb.: Peter, 2008. - 240 p. (In Russian)

4. Bauman Z. Retrotopiya [Retrotopia]. - Moskow: VTsIOM, 2019. - 160 p. (In Russian)

5. Vallerstajn I. Mirosistemnyj analiz [Mirosystem analysis]. - Moskow: Ed. House "Territory of the Future", 2006. — 248 p. (In Russian)

6. Inozemcev V. Neeffektivnoe. Bezzhalostnoe. Tvoe. Pochemu vse my zhivem v kommercheskom gosudarstve Putina [Ineffective. Ruthless. Your. Why we all live in the commercial state of Putin]. In. Snob ot 4 iyulya 2019 g. [Snob of July 4, 2019]. https://snob.ru/entry/179441/?from=mirtesen

7. Remchukov K. Vystuplenie na «Ekhe Moskvy» v peredache «Osoboe mnenie» ot 4 aprelya 2016 [Speech on "Echo of Moscow" in the program "Minority opinion" of April 2016]. (In Russian)

8. Rozin V. M. Tekhnika i tekhnologiya: ot kamennyh orudij do Interneta i robotov [Technique and technology: from stone tools to the Internet and robots]. Yoshkar-Ola, PSTU, 2016. - 280 p. (In Russian)

9. https://ru.wikipedia.org/wiki/План_Маршалла/ 


\title{
History lessons: modalities "regularity", "singularity", "whole"
}

\author{
Rozin V. M., \\ Doctor of Philosophy, Prof., Chief Researcher Institute of Philosophy RAS, \\ rozinvm@gmail.com
}

\begin{abstract}
Annotation: The article discusses the conditions for the conceivability of the idea of the lessons of history. To rely on empirical material, three cases are analyzed: how Z. Bauman formulates the lessons of history in the book "The Relevance of the Holocaust", some modern Russian political analysts, I. Stalin in the 1920s and 1930s last century. The author hypothesizes that the whole, which allows one to obtain correct knowledge about the lessons of history, is given by two additional discourses (cultural and civilizational). The features of these discourses and related modalities of thinking - regularity and singularity - are discussed. The above considerations are verified on the empirical example of the post-war history of Germany and the USSR.
\end{abstract}

Keywords: history, history lessons, thinking, reconstruction, culture, civilization, whole, regularity, singularity, forecasting. 